\title{
Hyperhomocyst(e)inaemia, but not MTHFR C677T mutation, as a risk factor for non-arteritic ischaemic optic neuropathy
}

\begin{abstract}
Martin Weger, Olaf Stanger, Hannes Deutschmann, Michael Simon, Wilfried Renner, Otto Schmut, Jürgen Semmelrock, Anton Haas
\end{abstract}

\begin{abstract}
Backgroundlaims-Hyperhomocyst(e)inaemia has been identified as a strong risk factor for stroke, myocardial infarction, and deep vein thrombosis. A point mutation of methylene tetrahydrofolate reductase (MTHFR C677T) has been associated with increased plasma homocyst(e)ine levels. To investigate whether hyperhomocyst(e)inaemia and/or MTHFR C677T mutation are associated with nonarteritic ischaemic optic neuropathy (NAION), a case-control study including 59 consecutive patients with NAION and 59 controls matched for age and sex was performed.
\end{abstract}

Methods-Fasting plasma homocyst(e)ine levels, MTHFR C677T genotypes, and plasma levels of folate and vitamin B-12 were determined.

Results-Mean plasma homocyst(e)ine levels were significantly higher in patients than in controls (11.8 (SD 5.7) $\mu \mathrm{mol} / 1 v 0.8$ (2.5) $\mu \mathrm{mol} / 1, \mathrm{p}=0.02)$. The odds ratio for patients with homocyst(e)ine levels exceeding the 95th percentile of control homocyst(e)ine levels was 5.8 (95\% CI 1.521.4). Mean plasma folate levels were significantly lower in patients than in controls (4.3 (1.7) $\mathrm{ng} / \mathrm{ml} v 5.5$ (1.9) $\mathrm{ng} / \mathrm{ml}, \mathrm{p}=$ 0.001 ), whereas plasma vitamin $\mathrm{B}-12$ levels did not differ significantly. Prevalence of the MTHFR C677T mutation was not significantly increased in patients with NAION compared with controls.

Conclusion-These results suggest that hyperhomocyst(e)inaemia, but not MTHFR C677T mutation is associated with NAION. Determination of plasma homocyst(e)ine levels might be of diagnostic value in patients with NAION. (Br F Ophthalmol 2001;85:803-806)

Department of Angiology

W Renner

Department of Laboratory Medicine J Semmelrock

Correspondence to: Martin Weger, MD, Department of Ophthalmology,

Auenbruggerplatz 4, 8036

Graz, Austria

martin.weger

(a)kfunigraz.ac.at

Accepted for publication 1 March 2001

Hyperhomocyst(e)inaemia is a major risk factor for cardiovascular disease and venous thrombosis. ${ }^{1-5}$ Recent studies suggested that elevated levels of plasma homocyst(e)ine (tHcy) may cause endothelial dysfunction, presumably by generation of increased oxidative stress and impairment of nitric oxide (NO) metabolism..$^{6-9}$ Furthermore, direct toxicity of tHcy on the endothelium has been demonstrated in animal studies. ${ }^{10} 11$

Homocyst(e)ine is a highly reactive sulphur containing amino acid deriving from the intracellular metabolism of methionine by removal of a single methyl group. It is either further metabolised by irreversible transsulphuration to cystathionine and cysteine or remethylated to form methionine again. ${ }^{12}$ This important remethylation pathway occurs mainly by means of 5-methyltetrahydrofolate, which is formed by a riboflavin dependent enzyme, 5,10 methylene tetrahydrofolate reductase (MTHFR), with folate as a cosubstrate.

Impairment of homocyst(e)ine remethylation is characterised by elevated levels of fasting plasma homocyst(e)ine. ${ }^{13}$ A common qualitative variant of the MTHFR enzyme resulting from a single amino acid substitution (alanine to valine, caused by a $677 \mathrm{C} \rightarrow \mathrm{T}$ nucleotide exchange) was identified in $1988 .{ }^{14}$ This genetic defect is defined by its in vitro heat sensitivity and causes an enzyme activity that is approximately $50 \%$ of the normal mean. ${ }^{15}$

Prevalence of homozygosity for the MTHFR C677T mutation ranges between $5-15 \%$ of subjects of white descent and may be associated with moderately elevated plasma homocyst(e)ine levels. ${ }^{16}{ }^{17}$ However, reports on an association between the C677T MTHFR variant and vascular disease have been conflicting. ${ }^{18} 19$

Non-arteritic ischaemic optic neuropathy (NAION) is an infarction of the optic nerve head caused by an insufficient blood supply to the posterior ciliary arteries. It is a common vision threatening disease, primarily affecting patients older than 55 years. ${ }^{20}$ Several risk factors for NAION have been identified, including arterial hypertension, diabetes mellitus, hypercholesterolaemia and hyperfibrinogenaemia. ${ }^{21}{ }^{22}$ However, not all cases can be fully explained by these factors alone and the precise pathomechanism of ischaemic optic neuropathy is still unknown.

Recently, hyperhomocyst(e)inaemia was suggested to be a novel risk factor for NAION. ${ }^{23}$ However, the number of patients enrolled in that study was small and MTHFR C677T genotypes were not determined. Salomon et al, who determined MTHFR C677T genotypes, did not find an association with NAION, but did not investigate the role of hyperhomocyst(e)inaemia in those patients. ${ }^{24}$

The aim of our study was therefore to determine the association of both hyperhomocyst(e)inaemia and the MTHFR C677T mutation in a larger cohort of patients with NAION. 
Material and methods

We studied 59 consecutive patients with NAION who met the inclusion criteria, and 59 controls matched for age and sex. All participants were seen at our department between January 1996 and April 2000 and gave written informed consent before enrolment. The study was approved by the ethics committee of the Karl-Franzens University, Graz.

Criteria for diagnosis of NAION included sudden visual loss, optic disc oedema followed by optic atrophy, relative afferent pupillary defect and visual field defects consistent with ischaemic optic neuropathy. Exclusion criteria for all subjects were an erythrocyte sedimentation rate above $40 \mathrm{~mm}$ in the first hour, a history of jaw claudication, headache of recent onset, scalp tenderness, fever, myalgias, anorexia, and weight loss. Subjects with liver or kidney dysfunction, malignancy, intake of vitamins, and other medication known to influence homocyst(e)ine plasma concentrations such as oestrogens, carbamazepine, phenytoin, antifolates, and tricyclic antidepressants were also excluded.

According to the exclusion criteria another 24 patients diagnosed with NAION were not enrolled in this study (13 for taking one or more of the above cited medications, five for malignancy, and six for impaired renal function). The control group consisted of 59 age and sex matched consecutive patients, who were referred to our department for other reasons than NAION and retinal vascular diseases.

Blood samples were drawn from the antecubital vein between 7 am and 8 am after an overnight fast of at least 8 hours. Samples for homocyst(e)ine determination were processed immediately, centrifuged at $4^{\circ} \mathrm{C}(3000 \mathrm{~g}$ for 10 minutes), and stored at $-70^{\circ} \mathrm{C}$ until analysis. Measurements of plasma homocyst(e)ine in EDTA plasma were performed using high performance liquid chromatography (HPLC) and fluorescence detection according to the method of Araki and Sako ${ }^{25}$ with modifications by Ubbink et $a l^{26}$ and Vester and Rasmussen. ${ }^{27}$ Because this procedure involved a reducing step, the method did not distinguish between homocysteine and its oxidised analogues. Therefore the measured moiety is referred to as homocyst(e)ine.

Vitamine B-12 and folate were determined with an Abbott Axysm analyser using a microparticle enzyme immunoassay (vitamin B-12) or an "ion capture" technology (folate).

Genomic DNA was extracted from peripheral blood lymphocytes by standard techniques and the MTHFR mutation analysis was performed by PCR-RFLP according to Frosst et $a l,{ }^{16}$ by a technician unaware of the status of the DNA sample.

\section{STATISTICAL ANALYSIS}

Descriptive statistics were used to calculate frequencies and percentage of discrete variables. Continuous data are given as mean (SD). We performed the Kolmogorov-Smirnov test to assess normal distribution and Levene's test for homogeneity of variances. Means were compared using independent samples $t$ test, while proportions were compared using $\chi^{2}$ test statistic or when appropriate Fisher's exact test. Odds ratios and 95\% confidence intervals were calculated as a measure of the association between ischaemic anterior optic neuropathy and homocyst(e)ine levels. Data were analysed using a cut-off level of 95th percentile of homocyst(e)ine level among control values. Allele frequencies were calculated by the gene counting method. All $\mathrm{p}$ values are two tailed and all confidence intervals (CIs) were calculated at the $95 \%$ level. A p value $<0.05$ was considered to be significant.

Statistical analysis was performed with the SPSS statistical package (SPSS version 9.0. 1998, Chicago, IL, USA).

\section{Results}

The study group consisted of 59 patients (28 females and 31 males). The mean age of patients was 69.1 (SD 8.2) years (range 53-88 years) and 69.7 (9.1) years (range $52-88$ years) in controls, respectively. Baseline parameters and clinical characteristics of both groups are shown in Table 1 . In the NAION group arterial hypertension and diabetes mellitus were significantly more frequent than in the control group $(\mathrm{p}=0.025)$

Mean plasma homocyst(e)ine levels were significantly higher in patients than in controls (Table 2). Hyperhomocyst(e)inaemia defined by the 95 th percentile of the homocyst(e)ine levels in the control group was determined as $14.01 \mu \mathrm{mol} / 1$.

Fourteen patients $(23.7 \%)$ were therefore classified as hyperhomocyst(e)inaemic compared with three $(5 \%)$ controls. The odds ratio for these patients was 5.8 (95\% CI 1.5-21.4). Five of $13(38.4 \%)$ patients with both eyes affected were hyperhomocyst(e)inaemic compared with nine of $46(19.6 \%)$ patients with unilateral involvement $(\mathrm{p}=0.27)$.

Table 1 Baseline characteristics of patients with NAION and controls

\begin{tabular}{|c|c|c|}
\hline & $\begin{array}{l}\text { NAION } \\
(n=59)\end{array}$ & $\begin{array}{l}\text { Controls } \\
(n=59)\end{array}$ \\
\hline Number & 59 & 59 \\
\hline Female & $28(47.5)$ & $28(47.5)$ \\
\hline Male & $31(52.5)$ & $31(52.5)$ \\
\hline Mean age (years (SD)) & $69.1(8.2)$ & $69.7(9.1)$ \\
\hline Range (years) & $53-88$ & $52-88$ \\
\hline \multicolumn{3}{|l|}{ Risk factors } \\
\hline Arterial hypertension & $30(50.8)^{\star}$ & $18(30.5)$ \\
\hline Diabetes mellitus & $18(30.5)^{\star}$ & $8(13.5)$ \\
\hline Stroke & $4(6.8)$ & $1(1.7)$ \\
\hline Coronary heart disease & $9(15.3)$ & $6(10.2)$ \\
\hline \multicolumn{3}{|l|}{ Smoking status } \\
\hline Past & $17(28.8)$ & $15(25.4)$ \\
\hline Current & $7(11.9)$ & $7(11.9)$ \\
\hline Never & $35(59.3)$ & $37(62.7)$ \\
\hline
\end{tabular}

Numbers are given as $\mathrm{n}(\%) ;{ }^{\star} \mathrm{p}<0.05$

Table 2 Mean plasma levels of homocyst(e)ine, folate, and vitamin B-12 in patients and controls

\begin{tabular}{llll}
\hline & $\begin{array}{l}\text { NAION } \\
(n=59)\end{array}$ & $\begin{array}{l}\text { Controls } \\
(n=59)\end{array}$ & $\begin{array}{l}\text { Significance } \\
\text { p value }\end{array}$ \\
\hline Homocyst $(\mathrm{e})$ ine $(\mu \mathrm{mol} / 1)$ & $11.8 \pm 5.7$ & $9.8 \pm 2.5$ & 0.020 \\
Plasma folate $(\mathrm{ng} / \mathrm{ml})$ & $4.3 \pm 1.7$ & $5.5 \pm 1.9$ & 0.001 \\
Vitamin B-12 $(\mathrm{pg} / \mathrm{ml})$ & $425.4 \pm 207$ & $458.5 \pm 277$ & 0.468
\end{tabular}

Results are given as mean (SD). 
Table 3 Prevalence of MTHFR genotypes in patients with NAION and controls

\begin{tabular}{llll}
\hline Genotype & $\begin{array}{l}\text { NAION } \\
(n=59)\end{array}$ & $\begin{array}{l}\text { Controls } \\
(n=59)\end{array}$ & $\begin{array}{l}\text { Significance } \\
\text { p value }\end{array}$ \\
\hline CC & $31(52.5)$ & $28(47.5)$ & $\mathrm{ns}$ \\
CT & $21(35.6)$ & $23(38.9)$ & $\mathrm{ns}$ \\
TT & $7(11.9)$ & $8(13.6)$ & $\mathrm{ns}$ \\
\hline
\end{tabular}

Numbers are given as $\mathrm{n}(\%) ; \mathrm{ns}=$ not significant.

Mean plasma folate levels were significantly lower in patients than in controls, whereas mean plasma vitamin B-12 levels did not differ significantly between patients and controls (Table 2).

Distribution of the MTHFR C677T mutation is shown in Table 3. The prevalence of the homozygous variant of thermolabile MTHFR (TT genotype) did not differ significantly between the two groups, and MTHFR genotypes were not significantly associated with different plasma homocyst(e)ine levels among patients or controls.

\section{Discussion}

The main finding of our study is that plasma homocyst(e)ine levels are significantly higher in patients with NAION than in controls. The prevalence of homozygosity for the MTHFR C677T mutation, however, does not significantly differ between the two groups.

Hyperhomocyst(e)inaemia is an independent risk factor for cardiovascular diseases comparable with hypercholesterolaemia and smoking. ${ }^{2}$ Plasma homocyst(e)ine levels may be influenced by various factors including nutritional deficiencies, diseases like renal insufficiency and malignancies, medications, and constitutional causes. ${ }^{28}$ Above all, folate and vitamin B-12 deficiencies are known to be strong determinants of plasma homocyst(e)ine concentrations. ${ }^{29}$

Furthermore, homozygosity (TT genotype) for the MTHFR C677T mutation was reported to be associated with higher homocyst(e)ine plasma levels, especially in the presence of suboptimal folate intake. ${ }^{17} 183031$

Nevertheless, the distribution of the TT genotype of the MTHFR mutation in our cohort did not significantly differ between the two groups. Moreover, plasma homocyst(e)ine levels in patients with the TT genotype were not significantly higher than in patients with other genotypes. We therefore assume that homozygosity for the MTHFR C677T mutation does not have a role in NAION, which confirms the findings of previous studies. ${ }^{24}{ }^{32}$

In our study patients suffering from NAION had significantly higher tHcy levels than controls. When calculating the 95th percentile of control homocyst(e)ine levels, 14 patients $(23.7 \%)$ exceeded this level. These patients had an approximately fivefold higher risk of suffering from NAION. Results from previous large scale studies suggest that the overall risk increase for vascular disease associated with homocyst(e)ine is dose dependent without threshold level. ${ }^{33}$ In a meta-analysis, including 27 studies relating homocyst(e)ine to atherosclerotic vascular disease, the odds ratio was estimated to increase 1.6 for every $5 \mu \mathrm{mol} / 1$ of elevated plasma homocyst(e)ine. ${ }^{2}$

Moreover, a recent study in 12 patients suggested an association between increased plasma homocyst(e)ine levels and NAION in patients under 50 years of age. ${ }^{34}$

Plasma folate levels are known to be a strong determinant of homocyst(e)ine levels and were significantly lower in our patients compared with controls. Therefore, the increased plasma homocyst(e)ine levels may reflect the low plasma folate levels. In contrast, plasma vitamin B-12 levels did not differ significantly between the two groups.

Hyperhomocyst(e)inaemia was shown to cause endothelial dysfunction by impairing synthesis and bioavailability of nitric oxide (NO). ${ }^{35}$ Because a balance between vasodilatation, partly mediated by $\mathrm{NO}$ and vasoconstriction, has been suggested to have an important role in the physiological blood flow of the optic nerve head, ${ }^{36}$ endothelial dysfunction caused by hyperhomocyst(e)inaemia could lead to insufficient perfusion and ischaemia of the optic nerve head.

Treatment of hyperhomocyst(e)inaemia is simple, safe, and effective through vitamin supplementation. The administration of 250 $\mu \mathrm{g} /$ day of folic acid has been shown to reduce plasma homocyst(e)ine levels by approximately $25 \% .^{37}$ Moreover, recent studies have shown a beneficial effect of folic acid supplementation on plasma homocyst(e)ine induced endothelial dysfunction in both healthy probands and in patients with vascular disease. $^{3839}$ Therapies designed to lower plasma homocyst(e)ine levels may therefore directly attenuate arterial endothelial injury and dysfunction.

The following limitations of our study have to be considered: firstly, the present study shares the general limitations of retrospective studies. Secondly, a methionine loading test, which is a provocation test and detects up to $27 \%$ of otherwise undiagnosed patients with hyperhomocyst(e)inaemia was not performed. ${ }^{40}$ It may be assumed that applying the methionine loading test in our patients would have resulted in an even stronger association between NAION and hyperhomocyst(e)inaemia.

In conclusion, our study demonstrates that mild hyperhomocyst(e)inaemia, but not the MTHFR C677T mutation, is a risk factor for non-arteritic ischaemic optic neuropathy.

Clearly, large scale prospective studies are needed to further determine the role of homocyst(e)ine in NAION and to investigate the potential benefit of homocyst(e)ine lowering treatment on the development of NAION.

1 Clarke R, Daly L, Robinson K, et al. Hyperhomocysteinemia: an independent risk factor for vascular disease. $N \mathrm{Engl}$ 7 Med 1991;324:1149-55.

2 Boushey CJ, Beresford SA, Omenn GS, et al. A quantitative assessment of plasma homocysteine as a risk factor for vascular disease. Probable benefits of increasing folic acid intake. $¥ A M A$ 1995;274:1049-57.

3 Graham IM, Daly LE, Refsum HM, et al. Plasma homocysteine as a risk factor for vascular disease: the European Concerted Action Project. fAMA 1997;277: 1775-81. 
4 Den Heijer M, Koster T, Blom HJ, et al. Hyperhomocysteinemia as a risk factor for deep-vein thrombosis. $N$ (

5 Ray JG. Meta-analysis of hyperhomocysteinemia as a risk factor for venous thromboembolic disease. Arch Intern Med 1998;158:2101-16.

6 Chambers JC, McGregor A, Jean-Marie J, et al. Acute hyperhomocysteinaemia and endothelial dysfunction. Lancet 1998;351:36-7.

7 Tawakol A, Omland T, Gerhard M, et al. Hyperhomocyst(e)inemia is associated with impaired endotheliumdependent vasodilatation in humans. Circulation 1997;95: $1119-21$

8 Loscalzo J. The oxidant stress of hyperhomocyst(e)inemia. $\mathcal{F}$ Clin Invest 1996;98:5-7.

9 Upchurch GR, Welch GN, Fabian AJ, et al. Homocyst(e)ine decreases bioavailable nitric oxide by a mechanism involving glutathione peroxidase. 7 Biol Chem 1997;272:17012-7.

10 Harker LA, Harlan JM, Ross R. Effect of sulfinpyrazone on homocysteine-induced endothelial injury and arteriosclehomocysteine-induced endothelial injury

11 Lentz SR, Sobey CG, Piegors DJ, et al. Vascular dysfunction in monkeys with diet-induced hyperhomocyst(e)inemia. $\mathscr{f}$ Clin Invest 1996;98:24-9.

12 Refsum H, Ueland PM, Nygard O, et al. Homocysteine and cardiovascular disease. Anпu Rev Med 1998;49:31-62.

13 Miller JW, Nadeau MR, Smith D, et al. Vitamin B-6 deficiency vs folate deficiency: comparison of responses to methionine loading in rats. Am f Clin Nutr 1994;59:1033-9.

14 Kang SS, Zhou J, Wong PW, et al. Intermediate homocysteinemia: a thermolabile variant of methylentetrahydrofolate reductase. Am f Hum Genet 1988;43:414-21.

15 Engbersen AM, Franken DG, Boers GH, et al. Thermolabile 5,10-methylenetetrahydrofolate reductase as a cause of mild hyperhomocysteinemia. Am 7 Hum Genet 1995:56: 142-50.

16 Frosst P, Blom HJ, Milos R, et al. A candidate genetic risk factor for vascular disease: a common mutation in methyl-

7 Gemmati D, Previati M, Serino ML, et al. Low folate levels and thermolabile methylenetetrahydrofolate reductase as a primary determinant of mild hyperhomocysteinemia in primary determinant of mild hyperhomocysteinemia in normal and thrombembo
Vasc Biol 1999;19:1761-7.

18 Verhoef P, Kok FJ, Kluijtmans LA, et al. The $677 \mathrm{C} \rightarrow \mathrm{T}$ mutation in the methylenetetrahydrofolate reductase gene: associations with plasma total homocysteine and risk of coronary atherosclerotic disease. Atherosclerosis 1997;132 105-13.

19 Anderson JL, King GJ, Thomson MJ, et al. A mutation in the methylenetetrahydrofolate reductase gene is not associated with increased risk for coronary artery disease or myocardial infarction. $\mathcal{F}$ Am Coll Cardiol 1997;30:1206-11.

20 Repka MX, Savino PJ, Schatz NJ, et al. Clinical profile and long-term implications of anterior ischemic optic neuropathy. Am f Ophthalmol 1983;96:478-83.

21 Hayreh SS, Joos KM, Podhajsky PA, et al. Systemic disease associated with nonarteritic anterior ischemic optic neuropathy. Am $\mathcal{f}$ Ophthalmol 1994;118:766-80.

22 Talks SJ, Chong NH, Gibson JM, et al. Fibrinogen, cholesterol and smoking as risk factors for non-arteritic terol and smoking as risk factors for
ischaemic optic neuropathy. Eye 1995;9:85-8.

23 Pianka P, Almog Y, Man O et al. Hyperhomocysteinemia in patients with nonarteritic anterior ischemic optic neuropathy, central retinal artery occlusion, and central retina vein occlusion. Ophthalmology 2000;107:1588-92.
24 Salomon O, Huna-Baron R, Kurtz S, et al. Analysis of prothrombotic and vascular risk factors in patients with nonarteritic anterior ischemic optic nerve neuropathy. Ophthalmology 1999;106:739-42.

25 Araki A, Sako Y. Determination of free and total homocysteine in human plasma by high-performance liquid chromatography with fluorescence detection. $\mathcal{F}$ Chromatogr 1987;422:43-52.

26 Ubbink JB, Hayward-Vermaak WJ, Bissbort S. Rapid highperformance liquid chromatography assay for total homocysteine levels in human serum. f Chromatogr 1991;565: 441-6.

27 Vester B, Rasmussen K. High-performance liquid chromatography for rapid and accurate determination of homocysteine in plasma and serum. Eur 7 Clin Chem Clin Biochem 1991;29:549-54.

28 Hankey GJ, Eikelboom JW. Homocysteine and vascular disease. Lancet 1999;354:407-13.

29 Selhub J, Jacques PF, Wilson PW, et al. Vitamin status and intake as primary determinants of homocysteinemia in an elderly population. $\mathcal{7} A M A$ 1993;270:2693-8.

30 Harmon DL, Woodside JV, Yarnell JW, et al. The common thermolabile variant of methylenetetrahydrofolate reductase is a major determinant of mild hyperhomocysteinemia. $Q \mathcal{F}$ Med 1996;89:571-7.

31 Malinow MR, Nieto FJ, Kruger WD, et al. The effects of folic acid supplementation on plasma total homocysteine are modulated by multivitamin use and methylenetetrahydrofolate reductase genotypes. Arterioscler Thromb Vasc Biol 1997; 17:1157-62.

32 Biousse V, Kerrison JB, Newman NJ. Is non-arteritic anterior ischaemic optic neuropathy related to homocysteine ? Br F Ophthalmol 2000;84:555.

$33 \mathrm{Ma}$ J, Stampfer MJ, Hennekens $\mathrm{CH}$, et al. Methylenetetrahydrofolate reductase polymorphism, plasma folate, homocysteine and risk of myocardial infarction in US physicians. Circulation 1996;94:2410-6.

34 Kawasaki A, Purvin VA, Burgett RA. Hyperhomocysteinemia in young patients with non-arteritic anterior ischaemic optic neuropathy. Br f Ophthalmol 1999;83:1287-90.

35 Stamler JS, Osborne JA, Jaraki O, et al. Adverse vascular effects of homocysteine are modulated by endotheliumderived relaxing factor and related oxides of nitrogen. 7 Clin Invest 1993;91:308-18.

36 Orgul S, Gugleta K, Flammer J. Physiology of perfusion as it relates to the optic nerve head. Surv Ophthalmol 1999;43(Supp1 1):S17-26.

37 Brattström L. Vitamins as homocysteine-lowering agents. $\mathcal{f}$ Nutr 1996;126:1276S-80S.

38 Title LM, Cummings PM, Giddens K, et al. Effect of folic acid and antioxidant vitamins on endothelial dysfunction in patients with coronary artery disease. $\mathcal{F} \mathrm{Am}$ Coll Cardiol 2000;36:758-65

39 Woo KS, Chook P, Lolin YI, et al. Folic acid improves arterial endothelial dysfunction in adults with hyperhomocysteinemia. I Am Coll Cardiol 1999;34:2002-6.

40 Bostom AG, Jacques PF, Nadeau MR, et al. Post methionine load hyperhomocysteinemia in persons with normal fasting total plasma homocysteine: initial results from the NHLBI Family Heart Study. Atherosclerosis 1995; 116:147-51 